\title{
Fallopian Tube Endometrioid Tumor
}

National Cancer Institute

\section{Source}

National Cancer Institute. Fallopian Tube Endometrioid Tumor. NCI Thesaurus. Code C40111.

A benign, borderline, or malignant epithelial tumor of the fallopian tube that is characterized by the presence of glands and/or cysts lined by neoplastic cells that resemble endometrial cells. 